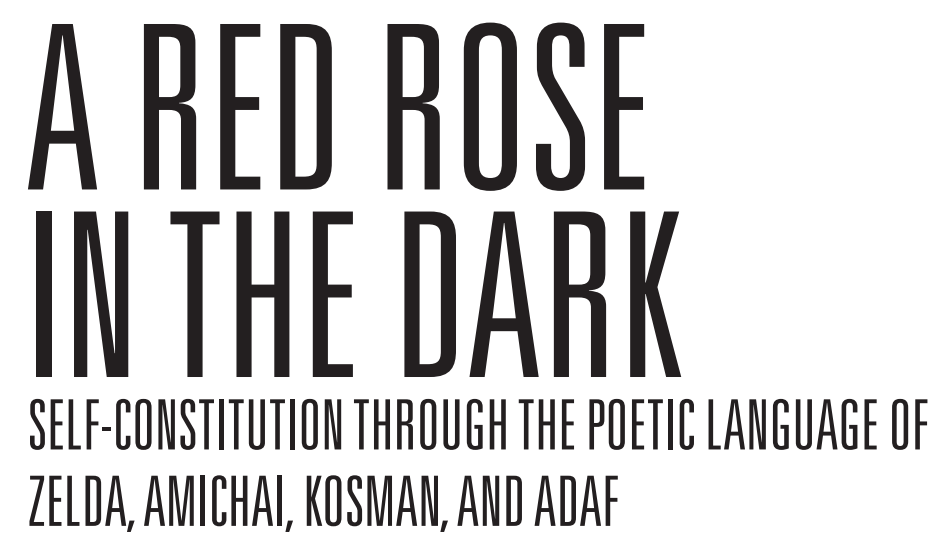


Emunot: Jewish Philosophy and Kabbalah

\section{SERIES EDITOR}

Dov Schwartz (Bar-Ilan University, Ramat Gan)

\section{EDITORIAL BOARD}

Ada Rapoport Albert (University College, London)

Gad Freudenthal (CNRS, Paris)

Gideon Freudenthal (Tel Aviv University, Ramat Aviv)

Moshe Idel (Hebrew University, Jerusalem)

Raphael Jospe (Bar-Ilan University, Ramat Gan)

Ephraim Kanarfogel (Yeshiva University, New York)

Menachem Kellner (Haifa University, Haifa)

Daniel Lasker (Ben-Gurion University, Beer Sheva)

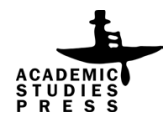




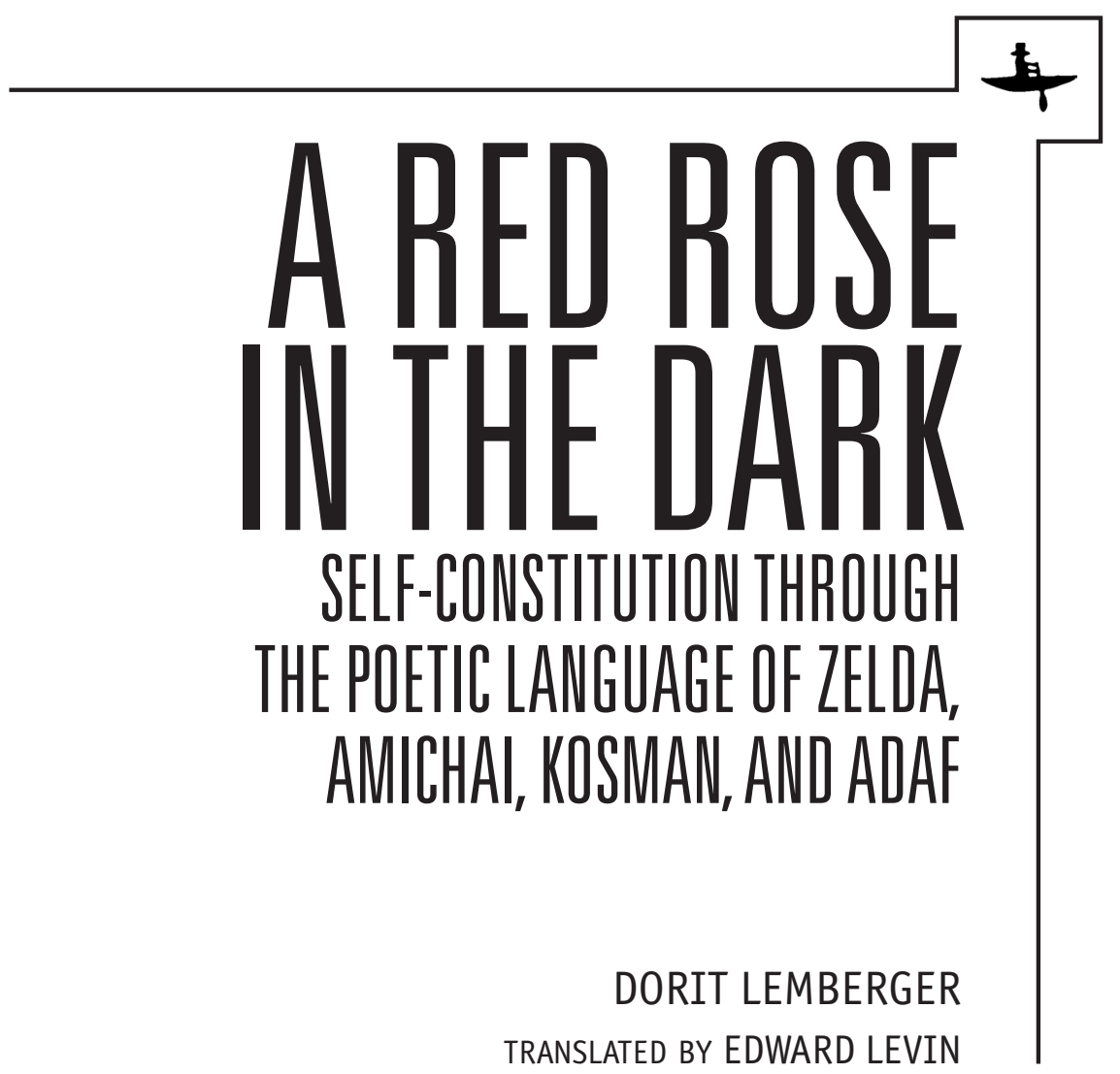

Boston

2016 
Library of Congress Cataloging-in-Publication Data:

A catalog record for this book is available from the Library of Congress.

ISBN 978-I-6I8I I-493-8 (hardback)

ISBN 978-I-6I 8I I-494-5 (electronic)

(C)Academic Studies Press, 2016

Cover design by Ivan Grave.

On the cover: "Heroic Roses," by Paul Klee, 1938.

Book design by Kryon Publishing, kryonpublishing.com

Academic Studies Press

28 Montfern Avenue

Brighton, MA 02135, USA

press@academicstudiespress.com

www.academicstudiespress.com 